\title{
Equatorial electrojet in east Brazil longitudes
}

\author{
R G Rastogi ${ }^{1}, \mathrm{H}_{\mathrm{CHANDRA}}{ }^{1, *}$ and $\mathrm{K}_{\mathrm{YumutO}}{ }^{2}$ \\ ${ }^{1}$ Physical Research Laboratory, Ahmedabad 380 009, India. \\ ${ }^{2}$ Space Environment Research Center, Kyushu University, Fukuoka, Japan. \\ *e-mail: hchandra@prl.res.in
}

\begin{abstract}
This paper describes the morphology of the equatorial electrojet (EEJ) along $45^{\circ} \mathrm{W}$ longitude in east Brazil, where the ground magnetic (dip) equator is associated with the largest declination in the world. Daily range of the horizontal field $(\Delta H)$, as expected, was largest at the station in the chain closest to the dip equator, Sao Luiz (inclination $-0.25^{\circ} \mathrm{S}$ ). $\Delta Z$ was largest positive at Eusebio (inclination $9.34^{\circ} \mathrm{S}$ ) and largest negative at Belem (inclination $7.06^{\circ} \mathrm{N}$ ); both near the fringe of EEJ belt. $\Delta Z$ at Sao Luiz during the daytime was unexpectedly large negative in-spite of a small dip and also located south of the dip equator where $\Delta Z$ should be positive. Center of EEJ was found to be shifted southward of the dip equator by about $1^{\circ}$ in latitude. During southern summer, $\Delta Y$ started decreasing from $00 \mathrm{~h}$ and reached a minimum value in the afternoon, an abnormal feature not discussed for any station so far. The mid-day value of the direction of $\Delta H$ vector was $22^{\circ}-24^{\circ} \mathrm{W}$ compared to the declination of $19^{\circ}-21^{\circ} \mathrm{W}$ in the region.
\end{abstract}

\section{Introduction}

The abnormally large solar daily range of the horizontal component of the geomagnetic field, $H$, at Huancayo and other equatorial stations was explained by Chapman (1951) as being due to a thin sheet of enhanced electric current in the $E$-region of ionosphere within $\pm 3^{\circ}$ dip latitude, named by him as 'equatorial electrojet' (EEJ). The enhanced current was explained as being because of an abnormally large electrical conductivity (Hirono 1952; Baker and Martyn 1953). The eastward electric field drives the vertical Hall current, which is inhibited due to the non-conducting atmosphere below and above. Thus vertical polarization field is set up, which significantly enhances the conductivity along east-west. Polarization field is not sustained beyond $3^{\circ}$ dip latitude as the electrons/ions can move vertically along the inclined magnetic field lines.

Equatorial electrojet has been extensively studied from ground, rocket and satellite based magnetometers, spaced receiver drift and VHF backscatter radar and theoretical studies (reviews by Forbes 1981; Reddy 1989; Rastogi 1989 and references therein). Features of EEJ have been described for longitude regions of $75^{\circ} \mathrm{W}$ (Forbush and Casaverde 1961), $15^{\circ}-19^{\circ} \mathrm{E}$ (Fambitakoye and Mayaud 1976a, 1976b), $75^{\circ} \mathrm{E}$ (Arora et al 1993; Rastogi 1999) and $5^{\circ} \mathrm{W}$ (Doumouya et al 1998). Still there is lack of information on the EEJ profile in South American region.

Teichi Kitamura with N B Trivedi had installed three component digital fluxgate magnetometers at a number of equatorial stations around the world. At present the chain is organized by K Yumuto of Kyushu University, Japan. Rastogi et al (2008) have described the features of EEJ along $60^{\circ} \mathrm{W}$ longitude sector using the data from six observatories in central Brazil. Rastogi and Trivedi (2009) have recently reported features of equatorial electrojet in east Brazil using limited data (16 quiet days) collected at a close network of 26 stations between $\pm 3^{\circ}$ dip latitude from November 1990 to March 1991. The present paper describes the features of EEJ along $45^{\circ} \mathrm{W}$ longitude

Keywords. Equatorial electrojet; Brazilian anomaly in equatorial electrojet; asymmetries in equatorial electrojet. 
based on extensive data during the period January 1993-December 1994 from four magnetic observatories of the Kyushu network. It is to be noted that the deviation of the $H$ field from the geographic north along the dip equator is largest in this sector.

\section{Data}

The geomagnetic field measurements by the threeaxis fluxgate magnetometers were the components pointing to magnetic north $\left(B_{H}\right)$, magnetic east $\left(B_{Y}\right)$ and vertically downward $(Z)$. The deviations at each hour from the midnight value $(00 \mathrm{~h}$ local time; $45^{\circ} \mathrm{WMT}$ ) have been converted into the geographic northward $(\Delta X)$ and geographic eastward $(\Delta Y)$ components using the relations described by Rastogi et al (2008). Though the results for central Brazil chain were described in magnetic north and magnetic east coordinates, the results for the present study are reported in geographic coordinates as it is widely used. For the declination angle of about $20^{\circ}$ for the stations, $\Delta X$ will be few percent smaller than the component along the magnetic north. $\Delta Y$ will have a contribution due to the magnetic northward component (about one third of it). Thus $\Delta X$ will represent the variations in the

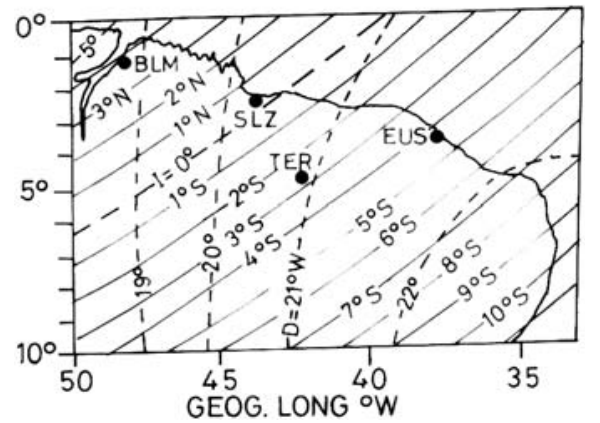

Figure 1. Map showing the locations of the stations for which data were used in the paper. amplitude of the electrojet current, $\Delta Y$ will decide the direction of the electrojet current.

The analysis used all the available data for individual stations for the period January 1993December 1994. The data were carefully screened and compared with quick look maps available at the website of Kyushu University. Only the days with complete 24 hourly values were used. To have a good statistics of data, all days with $A_{p}$ value of less than 20 were selected. As the $A_{p}<20$ corresponds to $K_{p}<4$, data includes moderately disturbed days also. This choice though reduces the standard error will lead to higher value of standard deviation due to larger day-to-day variability.

The locations of the stations used in the present analyses are shown in figure 1 . The iso-inclination lines are also drawn in the figure. The coordinates and other relevant data of the stations are given in table 1. The station closest to the dip equator was Sao Luiz (SLZ) with inclination of $0.25^{\circ} \mathrm{S}$. Stations close to the fringes of EEJ were Belem (BLM) with inclination of $7.06^{\circ} \mathrm{N}$ and Teresinia (TER) with inclination of $6.19^{\circ} \mathrm{S}$ and Eusebio with inclination of $9.34^{\circ} \mathrm{S}$. The data for Alcantra (ALC) with inclination of $0.02^{\circ} \mathrm{S}$ have been combined with that of SLZ as both the stations are very close-by (SLZ shifted to ALC due to increasing disturbances at SLZ). It is to be noted that during the period of study the magnetic declination at Brazilian stations were close to $20^{\circ} \mathrm{W}$ and the mean magnetic field intensity was slightly lower than in Peru.

\section{Results}

\subsection{Daily variations}

The daily variations of $\Delta X, \Delta Y$ and $\Delta Z$ during different days of April 1993 at SLZ and of the monthly means are shown in figure 2 . There is large day-to-day variability. The daily range in $X$ component varied between 60 and $160 \mathrm{nT}$

Table 1. Coordinates of stations used: IGRF year September-October 1994.

\begin{tabular}{|c|c|c|c|c|c|}
\hline Station name & Belem & Alcantara & Sao Luiz & Teresinia & Eusebio \\
\hline Station code & BLM & $\mathrm{ALC}$ & SLZ & TER & EUS \\
\hline Geog. lat. ${ }^{\circ} \mathrm{N}$ & -1.22 & -2.34 & -2.60 & -5.03 & -3.85 \\
\hline Geog. long. ${ }^{\circ} \mathrm{E}$ & -48.63 & -44.41 & -44.20 & -42.83 & -38.42 \\
\hline Geom. lat. & 1.94 & 0.67 & 0.95 & -0.54 & -0.81 \\
\hline Geom. long. & 25.35 & 29.33 & 29.63 & 29.48 & 34.59 \\
\hline Horizontal field $H \mathrm{nT}$ & 27223 & 26836 & 26783 & 25959 & 26111 \\
\hline Vertical field $Z \mathrm{nT}$ & 3372 & -9 & -118 & -2814 & -4303 \\
\hline$X$ field nT & 25760 & 25169 & 25117 & 24248 & 24292 \\
\hline$Y$ field $\mathrm{nT}$ & -8804 & -9311 & -9307 & -9267 & -9575 \\
\hline Inclination ${ }^{\circ} \mathrm{N}$ & 7.06 & -0.02 & -0.25 & -6.19 & -9.34 \\
\hline Declination ${ }^{\circ} \mathrm{W}$ & -18.87 & -20.30 & -20.34 & -20.92 & -21.51 \\
\hline
\end{tabular}




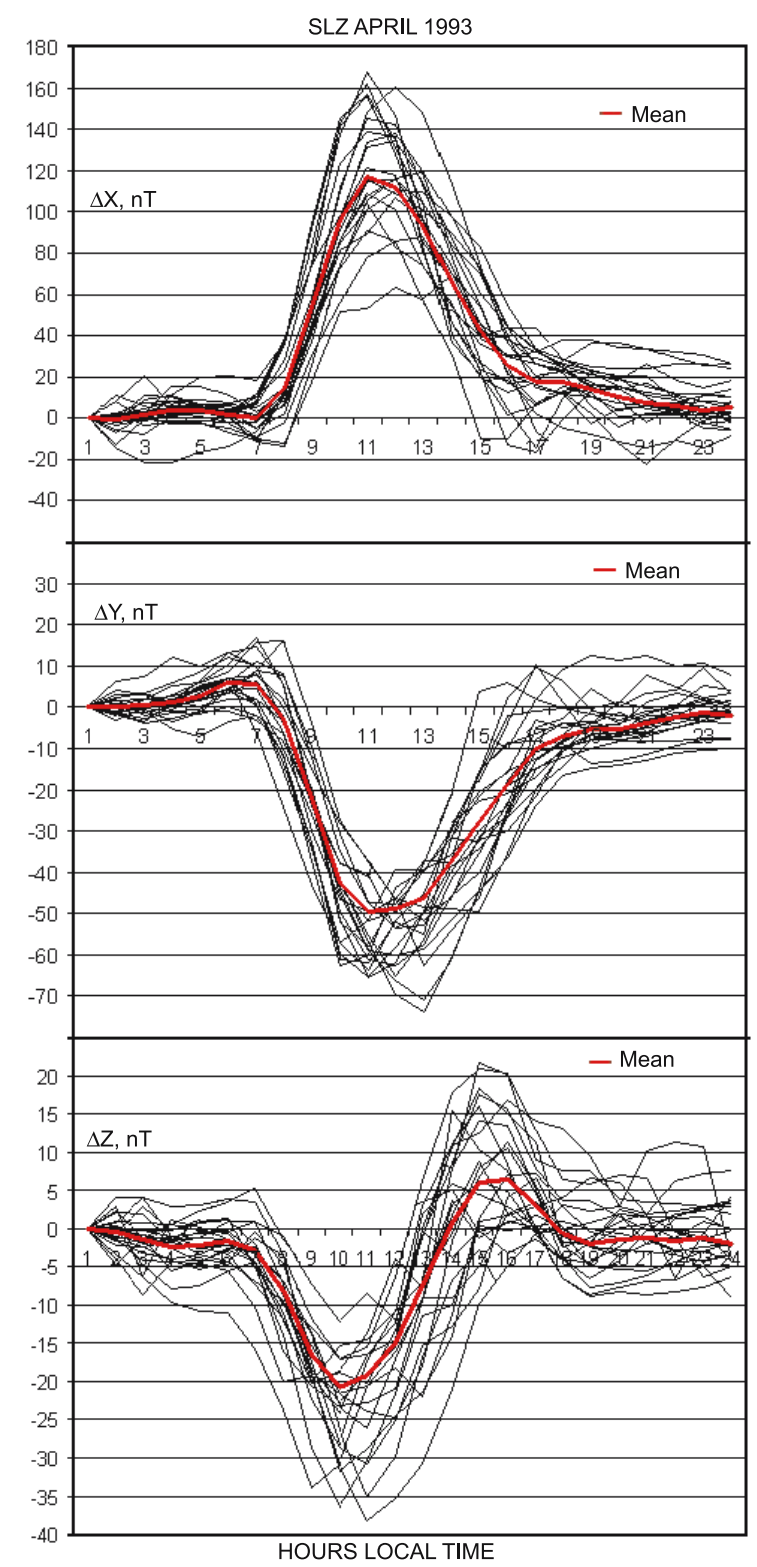

Figure 2. Daily variations of $\Delta X, \Delta Y$ and $\Delta Z$ (deviations in $X, Y$ and $Z$ components of the geomagnetic field) at Sao Luiz (SLZ) plotted for different days of April 1993. Mean daily variation is also shown in the figure.

with the time of maximum between 11 and $13 \mathrm{~h}$. The daily plots of $\Delta Y$ showed maximum negative values between 40 and $70 \mathrm{nT}$ around $09-13$. The maximum in $\Delta Z$ occurred between 09 and $11 \mathrm{~h}$ with values ranging from -15 to $-35 \mathrm{nT}$.

To have a quantitative estimate of the variability, the monthly mean values along with the standard error in mean $\sigma / \sqrt{n}$ and of the standard deviation $(\sigma)$ of $\Delta X, \Delta Y$ and $\Delta Z$ at each hour have been computed for the month of April 1993 for SLZ and are shown in figure 3 . The two curves adjacent to the mean are mean \pm standard error. The standard error in mean $\Delta X$ varied from around $8 \mathrm{nT}$ at noon to $5 \mathrm{nT}$ in the evening-midnight hours.

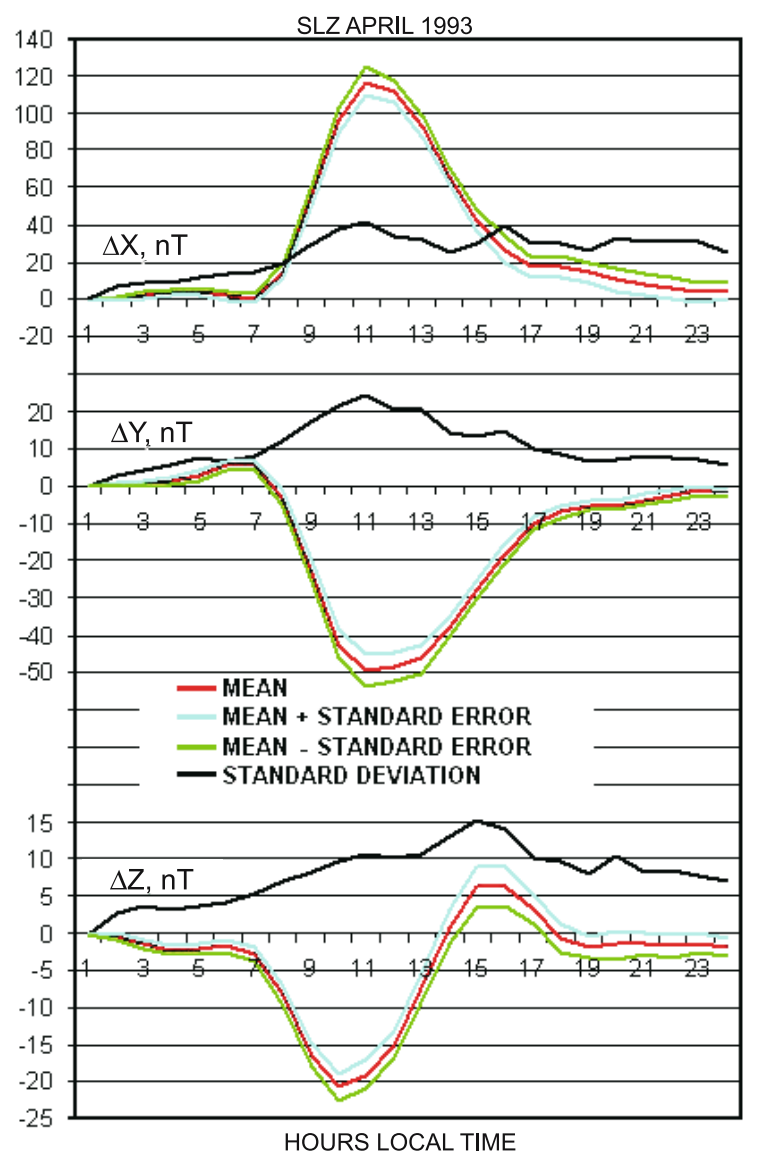

Figure 3. Monthly mean daily variations of $\Delta X, \Delta Y$ and $\Delta Z$ at SLZ for April 1993. The daily variations of the mean \pm the standard error in mean and the standard deviation are also shown in the figure.

The value of the standard error in mean $\Delta X$ was least in the midnight-morning hours (1-2 nT). The standard deviation was $40 \mathrm{nT}$ around noon and remained fairly high in the evening-midnight hours with values around $30 \mathrm{nT}$. The standard error in mean $\Delta Y$ was maximum around noon with a value of about $5 \mathrm{nT}$. The standard deviation was also maximum around noon with a value of $23 \mathrm{nT}$ and decreased to 7-8 $\mathrm{nT}$ in the evening-midnight hours. For $\Delta Z$ maximum values of the standard error and standard deviation, $3 \mathrm{nT}$ and $15 \mathrm{nT}$ respectively were around $17 \mathrm{~h}$. The high values of the standard deviations at noon are partly because of the dayto-day variability in the electrojet strength. Dayto-day variability in the electrojet is largely due to the variability in electric field through the variability in the neutral winds in atmosphere. Electric fields of magnetospheric origin could also add to this variability especially on disturbed days. The variability in the evening and around midnight will not have the regular component of the electrojet variability but primarily of irregular component.

The daily variation of the direction of the $H$ vector $(\theta)$ obtained from the monthly mean values 


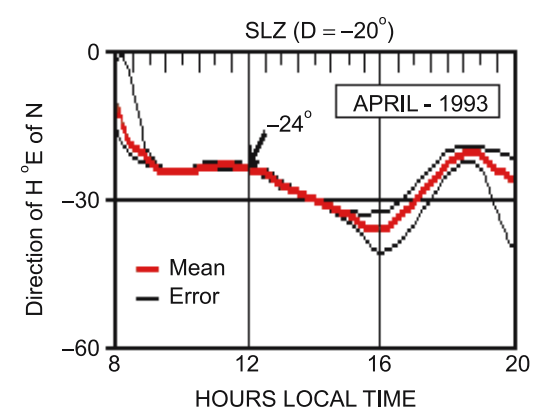

Figure 4. Monthly mean daily variation of the direction of the horizontal component of geomagnetic field $(\theta)$ at SLZ for April 1993. Also shown are the mean direction \pm the error in the direction.

of $\Delta X$ and $\Delta Y$ for SLZ during April 1993 is shown in figure 4 . Based on the mean values and standard errors in mean $\Delta X$ and $\Delta Y$ at SLZ, the errors in the direction of $H$ vector have been computed. The two curves adjacent to the mean value are the mean \pm error. The direction of the $H$ vector is plotted from 08 to $20 \mathrm{~h}$ only. Between $09 \mathrm{~h}$ and $15 \mathrm{~h}$ the three curves are almost identical implying very small error (about a degree). Also from 09 to $12 \mathrm{~h}$, the direction of the $H$ vector is close to $24^{\circ}$ west of north. In the afternoon, direction of the $H$ vector increases steadily reaching a value of more than $35^{\circ}$ at $16 \mathrm{~h}$. It again decreases to about $20^{\circ}$ at $18 \mathrm{~h}$ and later increases rapidly to very high values in the night (not shown in the figure as the error is very high due to low values of the deviations especially in $Y$ ). Mean value of $\theta$ for $12 \mathrm{~h}$ was $24^{\circ} \mathrm{W}$ compared to the declination of $19^{\circ} \mathrm{W}$. This can be further seen from the correlation of the deviations $\Delta X$ and $\Delta Y$ for SLZ-ALC. The mid-day values (mean of $11-13 \mathrm{~h}$ ) of $\Delta X$ and $\Delta Y$ for SLZ-ALC during the period March-May 1993 after removing the 27-day running mean are plotted in figure 5 . There was a close anti-correlation between the dayto-day changes in $\Delta X$ and $\Delta Y$ after removing the 27-day running mean. The positive values of $\Delta X$ were having more negative values in $\Delta Y$. The correlation coefficient of -0.87 indicates very good anti-correlation and the slope of the regression line is -0.44 corresponding to $\theta$ equal to $-24^{\circ}$.

The annual mean solar daily variations of the deviations in the northward $(\Delta X)$, eastward $(\Delta Y)$ and vertical $(\Delta Z)$ field components averaged over the selected quiet days of the months January to June at the four stations are shown in figure 6 . Regarding the $S_{q}(X)$ variations, the largest amplitude of $85 \mathrm{nT}$ was recorded at SLZ-ALC, station closest to the magnetic equator. The peak amplitude at these stations was at $11-12 \mathrm{~h}$. The peak amplitudes of $S_{q}(X)$ at other stations were about 55-60 nT, almost two thirds of that at SLZ-ALC. The maximum values of $\Delta X$ are lower compared to
140-150 nT reported by Rastogi and Trivedi (2009) for the higher solar activity period of 1990-1991. The most interesting feature was that, at any of the stations $\Delta X$ shows an increase from $00 \mathrm{~h}$ LT till the sunrise when the magnitude was of the order of 5-10 nT before the post-sunrise rapid increase. This feature was also reported for stations in central Brazil along $60^{\circ} \mathrm{W}$ (Rastogi et al 2008). Rastogi and Trivedi (2009) also observed increase of $\Delta H$ from midnight to sunrise period for SLZ and suggested that there could be additional sources of ionization in American longitudes other than solar radiations like solar charged particle precipitation in the region of low magnetic field. $\Delta X$ continued to decrease from mid-day through sunset period up to midnight hours.

The amplitude of $S_{q}(Z)$ as expected was largest negative $(-20 \mathrm{nT})$ at BLM, a station at the northern edge of EEJ and the largest positive $\Delta Z$ of $15 \mathrm{nT}$ at EUS, a station near the southern edge of EEJ. The $\Delta Z$ at SLZ was significantly negative $(-18 \mathrm{nT})$. This shows a strong latitudinal asymmetry in the EEJ profile along east Brazil longitudes in this Atlantic anomaly region. Results for 19901991 also showed this asymmetry with maximum $\Delta Z$ value of about $35 \mathrm{nT}$ in the southern edge of electrojet and $-70 \mathrm{nT}$ in the northern edge of electrojet (Rastogi and Trivedi 2009).

$\Delta Y$ values at any of the stations were negative suggesting northward meridional currents in this region. The amplitude was largest at SLZ-ALC $(-35 \mathrm{nT}$ at $12 \mathrm{~h} \mathrm{LT})$, which was almost $40 \%$ of the $\Delta X$. It must be noted that due to the declination of about $20^{\circ}$ and current flowing normal to declination, there will be a component of electrojet current that gives rise to $\Delta Y$ (about one third of the deviation in $H$ ). The maximum $\Delta Y$ values were about $-60 \mathrm{nT}$ for 1990-1991 (Rastogi and Trivedi 2009).

The northward component $\Delta X$ combined with corresponding $\Delta Y$ values were used to compute the direction $(\theta)$ of the $H$ vector for all the four stations. In figure $7(\mathrm{a})$, deviations $\Delta Y$ are plotted as a function of deviations $\Delta X$ for all the hours at each of the station. At EUS the resulting curve is almost a straight line pointing to a direction of about $22^{\circ}$ west of north. The curves for TER and SLZ-ALC are elongated ellipse with alignment close to $22^{\circ} \mathrm{W}$ of north. However, the curve is less elongated ellipse for BLM. The declinations at the four stations are also marked in the figure. The direction of the $H$ vector is almost along the declination. The length of the semi-major axis indicates the maximum value of the $H$ vector. For proportionate values of $\Delta Y$ with respect to $\Delta X$, it would be straight line. The width of the ellipse (semi-minor axis) is related to the relative value of the $\Delta Y$ and indicates the contribution 


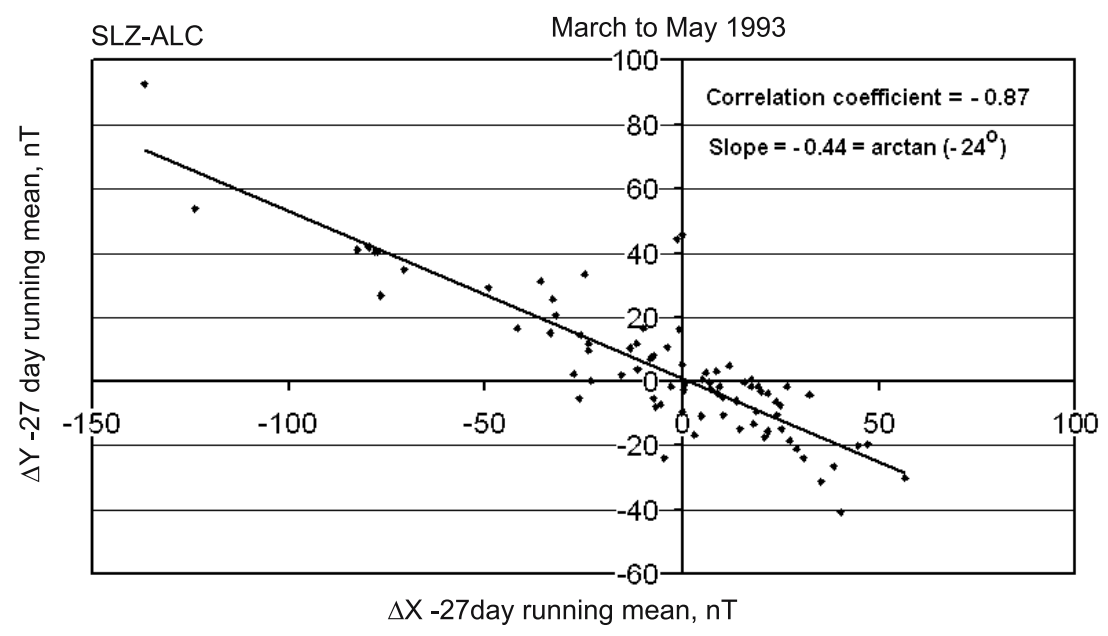

Figure 5. Scatter plot of the mid-day (11-13 h) values of $\Delta X$ and $\Delta Y$, after removing the 27-day running mean values for SLZ-ALC during the period 1 March-31 May, 1993. The correlation coefficient and slope are also indicated in the figure.

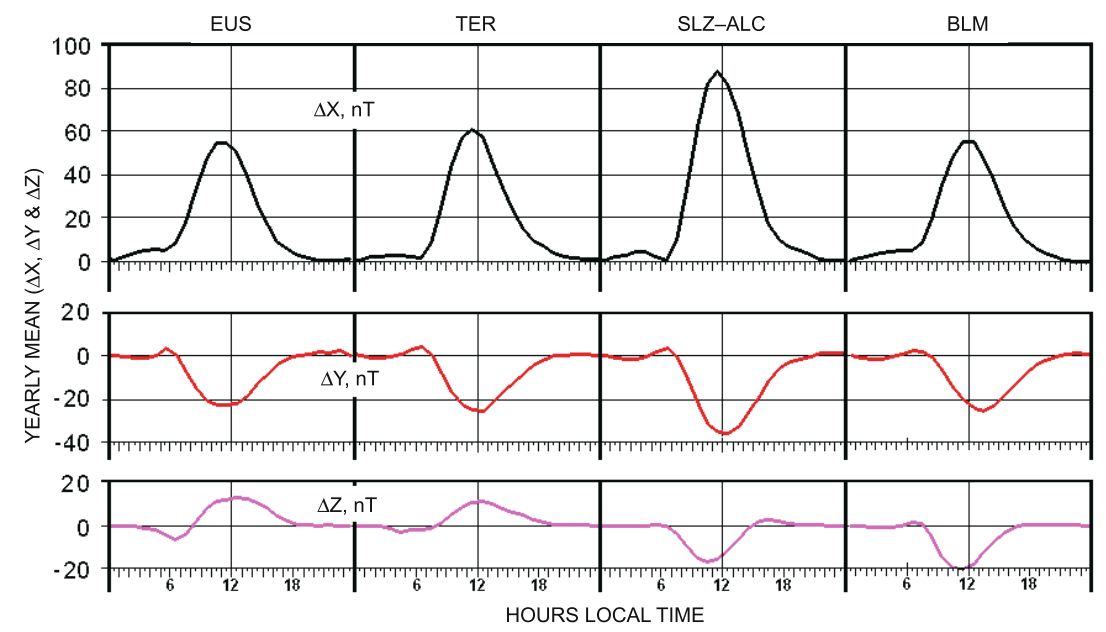

Figure 6. Annual mean daily variations of $\Delta X, \Delta Y$ and $\Delta Z$ at BLM, SLZ-ALC, TER and EUS averaged over selected quiet days for the period January 1993-December 1994.

due to the global Sq current on the total current at these stations. It must be noted that the declination was around $-20^{\circ}$ in this longitude sector. The departure from the declination during daytime was least for TER and gradually increased at EUS, SLZ-ALC and BLM. Rastogi and Trivedi (2009) observed mean direction of current to be $25^{\circ}$ west of north.

In figure $7(\mathrm{~b})$, the variations of the direction of $\Delta X$ and $\Delta Z$ vectors in the meridional plane during the course of the day for each of the stations are shown. It can be seen that at EUS (inclination $9.3^{\circ} \mathrm{S}$ ) and TER (inclination $6.2^{\circ} \mathrm{S}$ ), stations south of the dip equator, the loop is titled towards positive $Z$. At SLZ-ALC (inclination $0.5^{\circ} \mathrm{N}$ ) and BLM (inclination $7.1^{\circ} \mathrm{N}$ ), stations north of the dip equator, the loop is titled towards negative.

\subsection{Seasonal variations}

The mean daily variations for different seasons are studied next. Figure 8 shows the seasonal mean daily variations of $\Delta X, \Delta Y$ and $\Delta Z$ at the four stations. The amplitude of $\Delta X$ was highest at SLZ-ALC with peak values of about $100 \mathrm{nT}, 85 \mathrm{nT}$ and $78 \mathrm{nT}$ during $E$-months, $D$ months and $J$-months, respectively. At TER peak values were $70 \mathrm{nT}, 60 \mathrm{nT}$ and $50 \mathrm{nT}$ for $E$-months, $D$-months and $J$-months, respectively. At EUS peak values were $70 \mathrm{nT}, 50 \mathrm{nT}$ and $45 \mathrm{nT}$ during $E$-months, $J$-months and $D$-months, respectively. Almost similar values were at BLM with peak values of $68 \mathrm{nT}, 52 \mathrm{nT}$ and $46 \mathrm{nT}$ during $E$-months, $J$-months and $D$-months, respectively. Thus the well-known equinoctial maxima in EEJ current are clearly seen at these stations. 


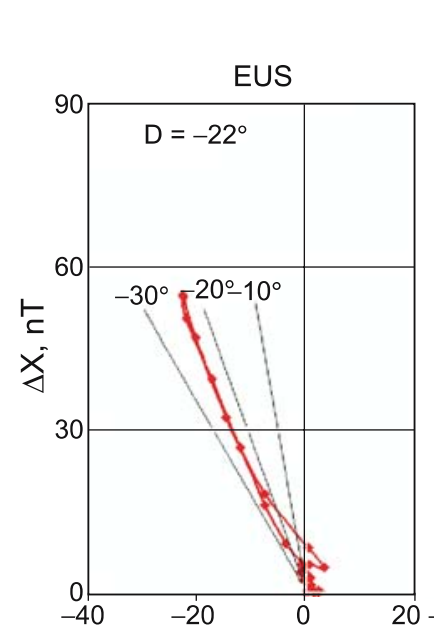

(a)

ANNUAL MEAN
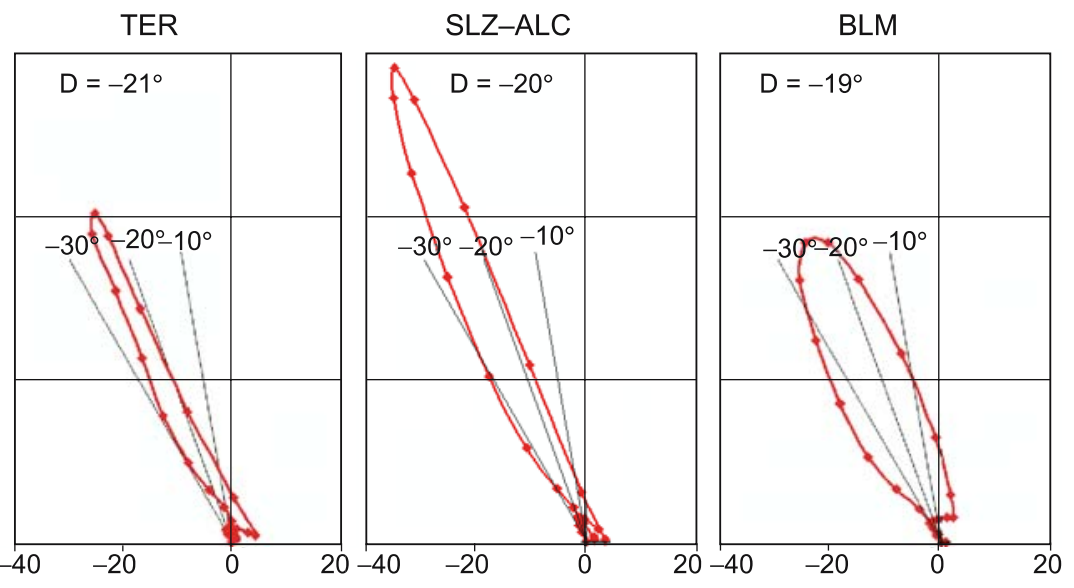

$\Delta \mathrm{Y}, \mathrm{nT}$

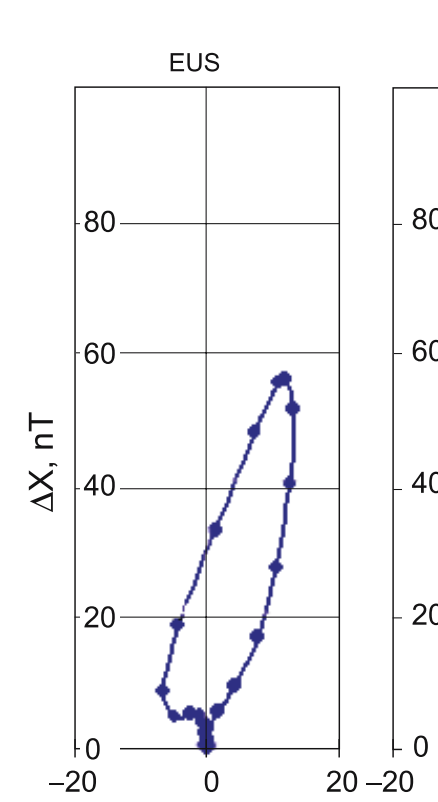

(b)
20

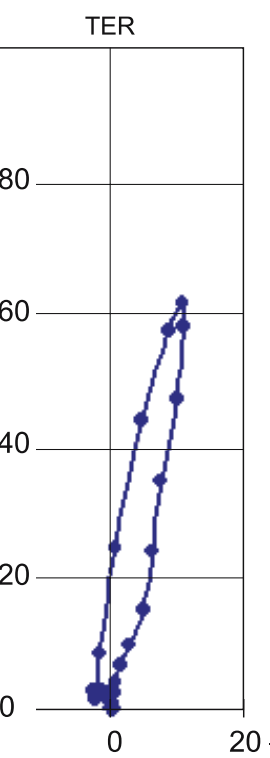

ANNUAL MEAN
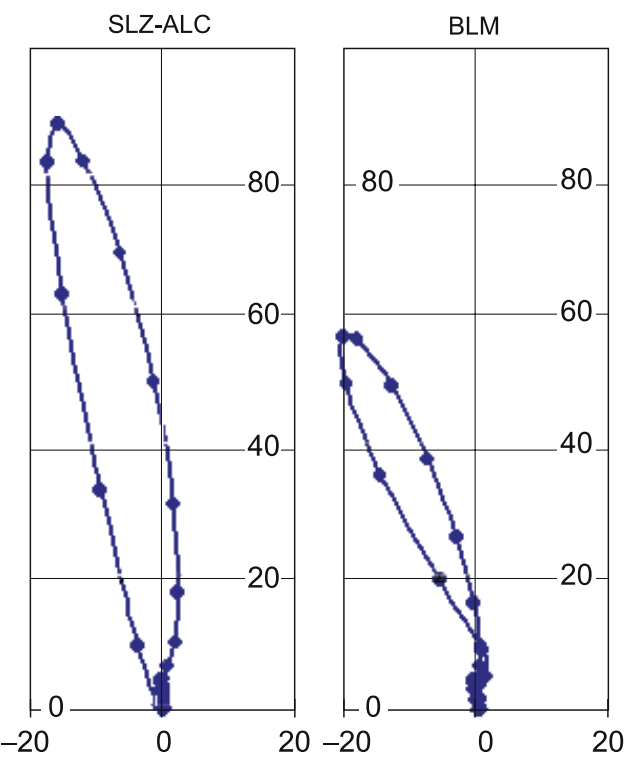

$\Delta \mathrm{Z}, \mathrm{nT}$

Figure 7. Diurnal plot of the annual mean values of (a) $\Delta X$ versus $\Delta Y$, and (b) $\Delta X$ versus $\Delta Z$ at BLM, SLZ-ALC, TER and EUS averaged over selected quiet days for the period January 1993-December 1994.

The daily variations of $\Delta Y$ show maximum negative values around noon and are highest during $E$-months and lowest during $D$-months. The values are highest at SLZ-ALC $(-45 \mathrm{nT}$, $-35 \mathrm{nT},-32 \mathrm{nT}$, during $E$-months, $D$-months and $J$-months, respectively) compared to the values of $-30 \mathrm{nT},-20 \mathrm{nT}$ and $-30 \mathrm{nT}$ for $E$-months, $D$ months and $J$-months, respectively at BLM. There is tendency of positive values in the early morning hours during $J$-months. Large positive $\Delta Y$ in the morning and negative $\Delta Y$ in the evening during $J$-months indicate that the effect of northern mid latitude current system at the stations. Interestingly no indications are seen of any maximum in the daily variations of $\Delta Y$ at these stations during the $D$-months when the Sun is south of the equator.

The deviations in $\Delta Z$ component show systematic change with latitude. The deviations are negative at BLM and SLZ-ALC with peak values of -15 to $-25 \mathrm{nT}$ but positive at TER and EUS $(10-20 \mathrm{nT})$. The time of maximum is different for different seasons.

The plots of the hourly values of $\Delta Y$ versus $\Delta X$ for different seasons are shown in figure 9. The points lie along elongated ellipse pointing to direction between $20^{\circ}$ and $30^{\circ}$ at EUS, TER and SLZ-ALC. At BLM the points lie between $10^{\circ}$ and $30^{\circ}$. The ellipses are aligned between $20^{\circ}$ and $30^{\circ} \mathrm{W}$ during $E$-months and 

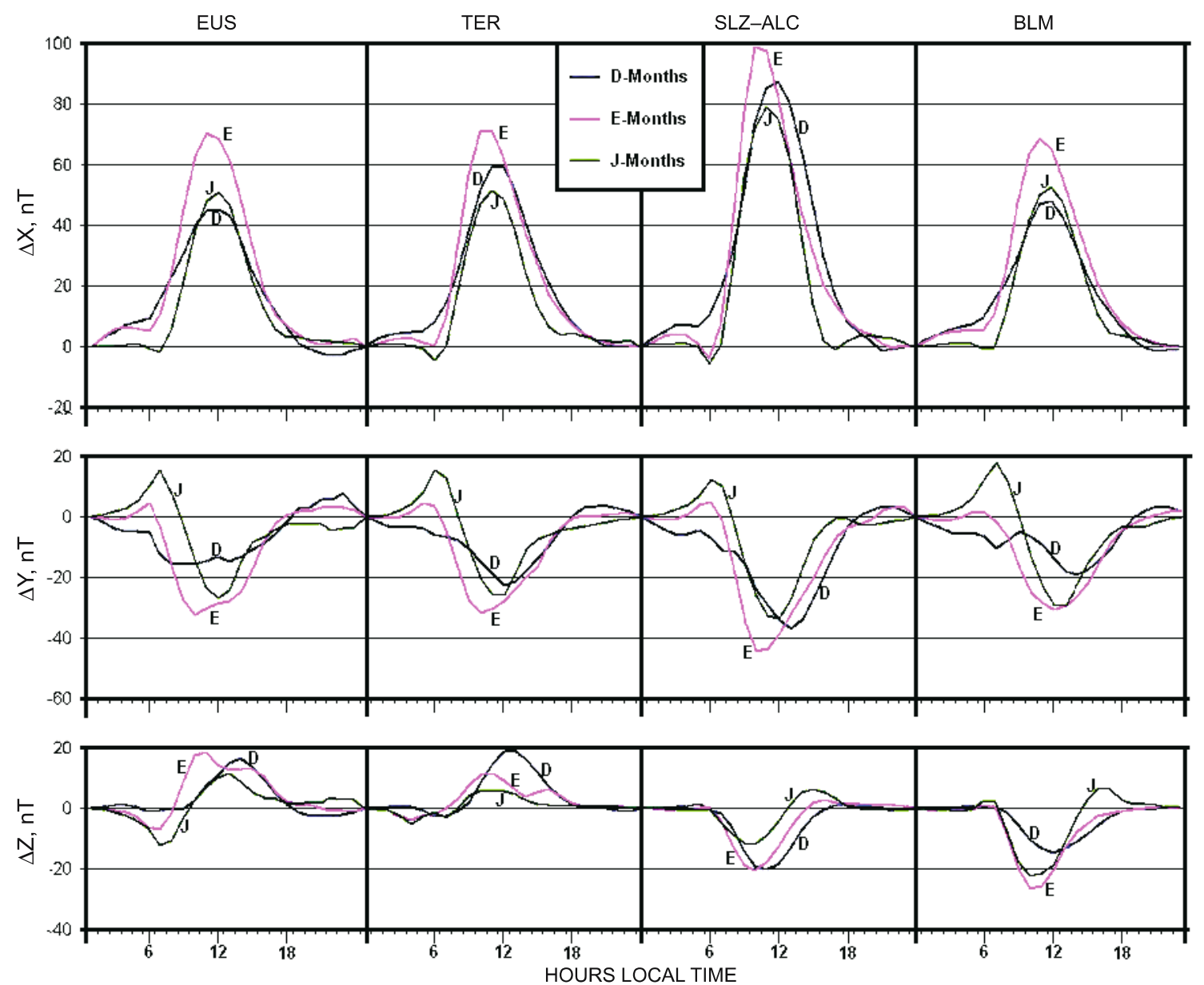

Figure 8. Seasonal mean daily variations of $\Delta X, \Delta Y$ and $\Delta Z$ at BLM, SLZ-ALC, TER and EUS averaged over selected quiet days for the period January 1993-December 1994.
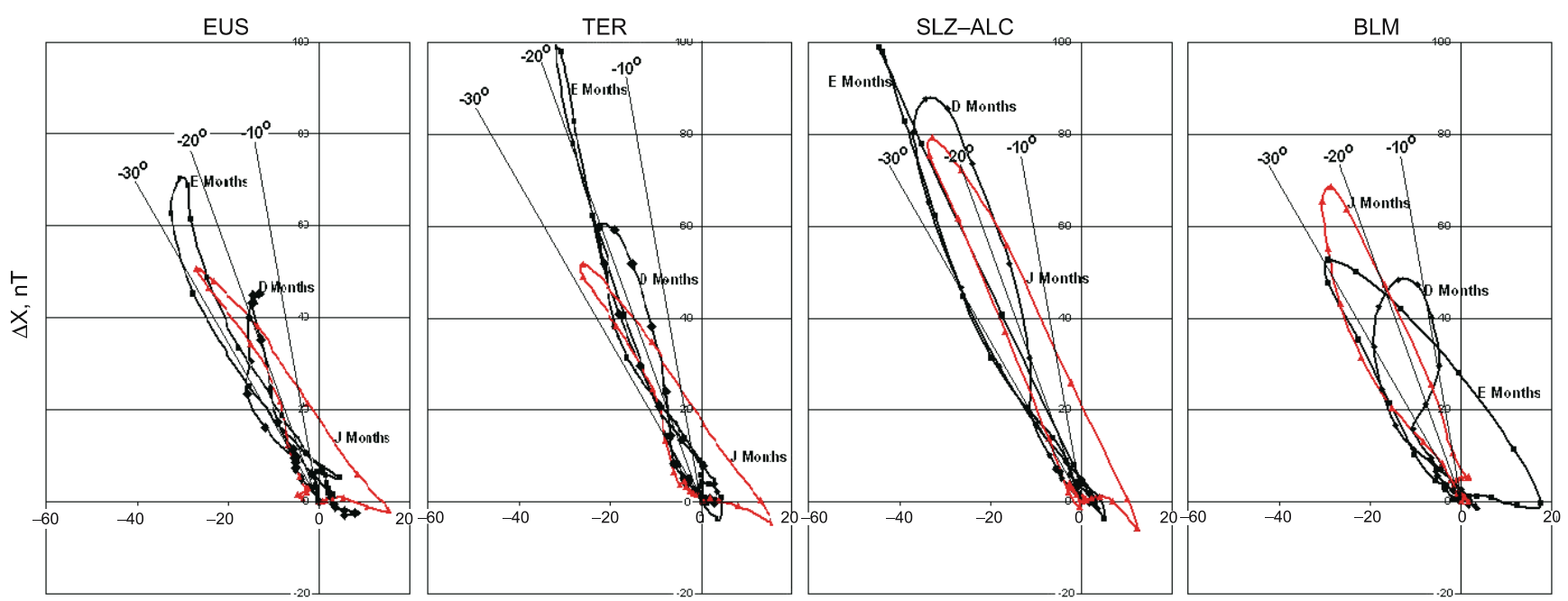

$\Delta \mathrm{Y}, \mathrm{nT}$

Figure 9. Diurnal plots of the seasonal mean values of $\Delta X$ versus $\Delta Y$ at BLM, SLZ-ALC, TER and EUS during $D$-months, $E$-months and $J$-months, averaged over selected quiet days for the period January 1993-December 1994.

$J$-months and between $10^{\circ}$ and $20^{\circ} \mathrm{W}$ during $D$-months at BLM. Due to this reason the annual average data showed wider ellipse for BLM. There are few points along other directions mainly of night hours when deviations in $Y$ were much smaller. 
Table 2. Mean values (10-14h) of $\Delta X, \Delta Y$ and $\Delta Z$ during different seasons.

\begin{tabular}{|c|c|c|c|c|c|c|c|c|c|}
\hline \multirow[b]{2}{*}{ Station } & \multicolumn{3}{|c|}{$\Delta X \mathrm{nT}$} & \multicolumn{3}{|c|}{$\Delta Y \mathrm{nT}$} & \multicolumn{3}{|c|}{$\Delta Z \mathrm{nT}$} \\
\hline & $D$ & $E$ & $J$ & $D$ & $E$ & $J$ & $D$ & $E$ & $J$ \\
\hline EUS & 39 & 58 & 40 & -14 & -27 & -19 & 11 & 8 & 7 \\
\hline TER & 50 & 58 & 41 & -18 & -25 & -18 & 13 & 8 & 4 \\
\hline SLZ-ALC & 74 & 77 & 64 & -29 & -37 & -25 & -16 & -13 & -5 \\
\hline BLM & 40 & 42 & 57 & -12 & -20 & -26 & -11 & -16 & -19 \\
\hline
\end{tabular}

\subsection{Latitudinal variations}

The seasonal mean daily maximum (10-14h) values of $\Delta X, \Delta Y$, and $\Delta Z$ for three seasons at all the stations are listed in table 2. $\Delta X$ was largest at SLZ-ALC. Seasonally the values were highest during equinoxes and lowest during $J$-months. $\Delta Y$ was negative at any of the stations and largest during equinoxes. $\Delta Z$ as expected was positive at EUS and TER situated south of the magnetic equator. $\Delta Z$ being negative at SLZ-ALC and BLM was again consistent with Chapman model of EEJ. The center of EEJ (extrapolated as $Z=0$ ) lies between TER and SLZ-ALC around $2^{\circ} \mathrm{S}$ dip ( $1^{\circ}$ latitude).

\section{Summary and discussion}

Geomagnetic data at a chain of stations in east Brazil are analyzed to provide the first detailed study in this region of high declination $\left(20^{\circ} \mathrm{W}\right)$. As expected the daily range in $X$ is largest for the station closest to the dip equator with equinoctial maxima. The amplitude of $\Delta Z$ was largest positive at Eusebio and largest negative at Belem, stations near the fringe of EEJ belt. The center of EEJ was shifted south of the dip equator by about $1^{\circ}$ in latitude. Rastogi and Trivedi (2009) also reported the center of electrojet near $1^{\circ} \mathrm{S}$ dip latitude in east Brazil during the period November 1990-March 1991 based on a limited dataset of 16 days within $\pm 3^{\circ}$ dip latitude. In the central Brazil longitude sector, center of the EEJ was $0.25^{\circ} \mathrm{S}$ in latitude of the dip equator in the morning hours and shifted gradually to $1.5^{\circ} \mathrm{S}$ in latitude in the evening hours (Rastogi et al 2008).

The direction of the $H$ vector at all the stations was close to the declination (along the magnetic north) around mid-day and shifted to several degrees east of north in the morning and evening hours. The deviations of the horizontal vector from the geographic north around noon were $22^{\circ}-24^{\circ} \mathrm{W}$ compared to the declination of $19^{\circ}-21^{\circ} \mathrm{W}$ in the region. This difference of about $3^{\circ}$ is suggested to be due to a northward meridional current at these stations, being close to the South Atlantic Anomaly region. Rastogi and Trivedi (2009) from data during November 1990-March 1991 reported the direction of current to be $25^{\circ} \mathrm{N}$ of east at the center of electrojet and $20^{\circ} \mathrm{N}$ of east at the edges of electrojet. Rastogi (2006) showed that the Sq $H$ vector at M B'our (declination $9.3^{\circ} \mathrm{W}$ ) pointed towards the direction of $33^{\circ} \mathrm{W}$ of north. This result indicated an anomaly in the variations of meridional current in the longitude sector between Europe and South America. Baker and Martyn (1953) had implicitly taken the dipole structure of the Earth's magnetic field with zero declination. They derived the latitudinal variation of the conductivity always being normal to the vertical polarization field. The theoretical implication of the present results is that the conductivity is largest in the direction normal to vertical as well as to the direction of the horizontal component of the geomagnetic field. There is a need for theoretical studies of the zonal as well as the meridional components of the conductivity for the region where the magnetic and geographic meridians are not coincident.

Electrodynamics plays an important role in the equatorial and low latitude ionosphere. In the absence of regular measurements electrojet has been used as an index of the electric field. High conductivity in the electrojet region during daytime makes electrojet as a sensitive indicator of the changes in the electric field. There are ample observations indicating that the EEJ is associated with space weather as with terrestrial atmospheric winds. EEJ is a sensitive indicator of the changes of electric field, therefore, an important tool to study the space weather effects. To understand and isolate the effects of these different sources a better distribution of stations in the EEJ belt is needed especially in the magnetic anomaly region of Brazil and West Africa. It is felt that a systematic study of the geomagnetic/ionospheric observations at suitable sites in Brazil is important to understand EEJ and aspects of space weather.

\section{Acknowledgements}

The data from the Kyushu network of equatorial electrojet stations is acknowledged. Rastogi and Chandra are thankful to the Director, Physical Research Laboratory, Ahmedabad for the facilities 
provided. Thanks are also due to the Indian Space Research Organization for the financial support.

\section{References}

Arora B R, Mahashabde M V and Kalra R 1993 Indian IEEY geomagnetic observational program and some preliminary results; Rev. Brazil Geofis. 11 365-385.

Baker W G and Martyn D F 1953 Electric currents in the ionosphere, 1, the conductivity; Phil. Trans. Roy. Soc. A246 281-294.

Chapman S 1951 The equatorial electrojet as detected from the abnormal electriccurrent distribution above Huancayo, Peru and elsewhere; Arch. Meterol. Geophys. Bioklimatol A4 368-390.

Doumouya V, Vassal J, Cohen Y, Fambitakoye O and Menvielle M 1998 Equatorial electrojet at African longitudes: First results from magnetic measurements; Ann. Geophys. 16 658-676.

Fambitakoye O and Mayaud P N 1976a Equatorial electrojet and regular daily variations of SR-I. A determination of the equatorial electrojet parameters; J. Atmos. Terr. Phys. 38 1-17.

Fambitakoye O and Mayaud P N 1976b Equatorial electrojet and regular daily variations SR-II. The centre of the equatorial electrojet; J. Atmos. Terr. Phys. 38 19-26.
Forbes J M 1981 The equatorial electrojet; Rev. Geophys. Space Phys. 19 469-504.

Forbush S and Casaverde M 1961 Equatorial electrojet in Peru; Carnegie Institution of Washington Report No. 620.

Hirono M 1952 A theory of diurnal magnetic variations in equatorial regions and conductivity of the ionospheric $\mathrm{E}$ region; J. Geomagn. Geoelec. 4 7-21.

Onwumechili C, Kawasaki A and Akasofu S I 1973 Relationship between the equatorial electrojet and polar magnetic variations; Planet. Space. Sci. 21 1-16.

Rastogi R G 1989 The equatorial electrojet: Magnetic and ionospheric effects in Geomagnetism (ed.) Jacobs J, Academic Press 3 461-525.

Rastogi R G 1999 Ionospheric current system in IndoRussian longitude sector; Science and Culture $\mathbf{6 5}$ 269-282.

Rastogi R G 2006 Sq and sfe currents at equatorial stations along the western and eastern African sectors; Earth Planets Space 58 1475-1478.

Rastogi R G, Chandra H, James M E, Kitamura K and Yumuto K 2008 Characteristics of equatorial electrojet in central South America; Earth Planets Space 60 623-632.

Rastogi R G and Trivedi N B 2009 Asymmetries in the equatorial electrojet around N-E Brazil sector; Ann. Geophys. 27 1-17.

Reddy C A 1989 The equatorial electrojet; PAGEOPH 131 485-508. 